\title{
Preparation and Characterization of Silymarin Nanocrystals and Phytosomes with Investigation of their Stability using Gamma Irradiation
}

\author{
Ahmed Ibrahim El-Batal' ${ }^{1}$, Shahira F Elmenshawi², Ahmed M Abdelhaleem Ali ${ }^{3}$, Enas Goodha \\ Eldbaiky ${ }^{1}$ \\ 1Drug Radiation Research Department, National Center for Radiation Research and Technology (NCRRT), Atomic Energy Authority, \\ Cairo, EGYPT. \\ ${ }^{2}$ Department of Pharmaceutics, Faculty of Pharmacy, Beni-Suef University, Beni-Suef, EGYPT.
}

\begin{abstract}
Introduction: In this study, Silymarin exhibits poor water solubility so, we developed drug delivery system. Different formulation strategies have been proposed for this problem. Materials and Methods: We were study the preparation of silymarin by dissolving it in different solvent (acetone,acetonitrile ,ethanol and methanol) to form nanocrystal and combination between lecithin and silymarin to prepare phytosome. And determined physicochemical characterization including dissolution, drug content in crystals or phytosome. On the other hand, the effect of gamma irradiation had been evaluated. Determination of crystal morphology was undertaken using SEM and TEM. Solid state was characterized by XRD, DSC and FT-IR. Particle size was determined using DLS and in-vitro drug release was evaluated for the prepared nanocrystals and phytosomes. Results: Indicated that the nanocrystal (NCy6) and phytosome (Phy1) significantly increased the solubility of silymarin by 17.12 and $35.59 \%$, respectively. The nanocrystals and phytosomeshavea small size (31.9 nm; Ncy6) and (186.7 nm; Phy1), also, XRD data showing semicrystalline state of (Ncy6) and amorphous nature of phytosomes. We noted that, the two dissolution formulations exhibited highest dissolution profile. Gamma radiation induced physical changes in the amorphous structure leading to semicrystalline and crystalline forms that, caused a decrease in drug solubility. We found that, nanocrystals and phytosomes could be considered as successful strategies for enhancing properties of Silymarin, and may be used as sustained release after radiation..
\end{abstract}

Key words: Silymarin, Nanocrystals, Phytosomes, Gamma irradiation, in-vitro dissolution.

\section{INTRODUCTION}

Owing to the importance of solubility and good bioavailability for oral drug delivery technology for oral drug, ${ }^{1-2}$ formulation researches face a great challenge. Thus, several strategies have been proposed to improve solubility and drug release include complexion with cyclodextrin, ${ }^{3}$ liposome, ${ }^{4}$ polymeric nanoparticles ${ }^{5}$ and micelles. ${ }^{6}$

Several manufactured nanoparticles mean particles with one dimension less than 100 $\mathrm{nm}^{4-5}$ Bulk materials of the same composition, mostly due to the increased specific surface area and reactivity, which may lead to increased bioavailability, solubility and toxicity. ${ }^{7}$ Drug nanocrystals can be defined as formula in crystals shape with a size in the nanometer range. ${ }^{8}$ There are various possibilities to produce nanocrystals in the desired shape and size. Three main principles were reported for preparation of nanocrystals, namely milling, precipitation and homogenization methods, as well as a combination of both techniques. ${ }^{9-11}$

It was reported that phytosomes are celllike structures "Phyto" means plant while "some" means cell like. ${ }^{12-13}$ Phytosomes are advanced herbal products produced by binding individual component of herbal extract
Submission Date: 21-10-2017; Revision Date: 24-01-2018; Accepted Date: 14-08-2018

DOI: 10.5530/ijper.52.4s.96 Correspondence:

Prof. Ahmed I. El-Batal, Drug Radiation Research Department, National Center for Radiation Research and Technology (NCRRT), Atomic Energy Authority, Cairo, EGYPT.

Phone: +202 22875924 +20222876033;

E-mail: aelbatal2000@gmail. com

Ahmed.Elbatal@eaea.org.eg

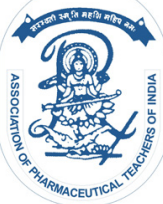

www.ijper.org 
to phosphatidylcholine resulting in a product that is better absorbed and produces better results than the conventional herbal extracts. ${ }^{13}$ The phospholipid molecular structure includes a water-soluble head and two fat-soluble tails. ${ }^{14}$ Because of this dual solubility, the phospholipid acts as an effective emulsifier. ${ }^{13}$ Therefore, phytosomes provide dramatically enhanced bioavailability for lipid soluble drugs, ${ }^{7}$ and ${ }^{15}$ explained by faster and improved absorption in the intestinal tract. ${ }^{16}$

Two types of radiation are commonly differentiated in the way they interact with normal chemical matter: ionizing and non-ionizing radiation. ${ }^{17}$ The effects of radiation as a method of sterilization on the physicochemical properties of solid drugs have to be addressed in order to avoid solid state changes during storage and/ or further processing of the drugs in the manufacturing pathway. ${ }^{18-20}$

Silymarin consists of a family of flavonoids (silybin, isosilybin, silychristin, silydianin and taxifoline) commonly found in the dried fruit of the milk thistle plant Silybum marianum. ${ }^{21}$ Although silymarin has a role as an antioxidant and hepatoprotective it is also well known for its role as an anticancer agent. ${ }^{16,21}$ Silymarin absorption rate levels vary between 20 and 50\%. ${ }^{2}$ Silybin (60\% of the silymarin extract) is slightly soluble in water and oil. It has poor permeation across the intestinal epithelial cells and minor gastrointestinal (GI) tract absorption in rats has been reported. ${ }^{22}$ Several reasons have been attributed for this poor bioavailability, e.g., poor internal absorption, ${ }^{21}$ degradation by gastric fluid, ${ }^{16}$ or its poor solubility. ${ }^{23-25}$

This study addressed developing formulations of silymarin in order to improve its water solubility and enhance its oral bioavailability using two recent techniques. Nanocrystals and phytosomes's formulation were prepared, investigated for their chemical and physical properties. Also, the effect of gamma radiation on selected formulations was carried out to determine its sterility and stability.

\section{MATERIALS AND METHODS}

\section{Materials}

Silymarin was purchased from Arab Company for Pharmaceuticals and Medicinal plant (MEPACO- MED), Cairo, Egypt. Ethanol, acetone, acetonitrile and methanol HPLC Grade solvents that were purchased from SigmaAldrich Company.

\section{Preparation of Silymarin Nanocrystals}

Nanocrystal formulations of Silymarin were prepared according to a method reported in the literature (26-27) by adding $250 \mathrm{mg}$ of silymarin to several organic solvents namely acetone, acetonitrile, ethanol and methanol followed by vigorous mixing for $30 \mathrm{~min}$. The mixture was then added drop wise to distilled water with mixing at $1000 \mathrm{rpm}$ for $30 \mathrm{~min}$ at temperature $30 \pm 2^{\circ} \mathrm{C}$.

The phase volume ratio between the organic and aqueous phases was varied according to values mentioned in Table 1 . The final nanocrystals were obtained by evaporating the solution using either hot air oven or by vacuum rotary evaporator. ${ }^{26-27}$

\section{Preparation of Silymarinphytosomes}

Two methods were used for the preparation of silymarinphytosomes; the mixing method and co-grinding

Table 1: Composition of Silymarin Nanocrystals' formulations.

\begin{tabular}{|c|c|c|c|c|c|c|}
\hline Formula & $\begin{array}{c}\text { Silymarin } \\
(\mathbf{m g})\end{array}$ & $\begin{array}{c}\text { Water } \\
(\mathbf{m L})\end{array}$ & $\begin{array}{c}\text { Org. Solvent } \\
(\mathbf{m L})\end{array}$ & $\begin{array}{c}\text { Vol. } \\
\text { Ratio(v/v) }\end{array}$ & Evaporation & $\begin{array}{c}\text { Evaporation } \\
\text { temp. }\left({ }^{\circ} \mathbf{C}\right)\end{array}$ \\
\hline Nc1 & 250 & 200 & Acetone (4) & $1: 50$ & Hot air oven & a \\
\hline Nc2 & 250 & 400 & Acetonitrile (8) & $1: 50$ & Hot air oven & a \\
\hline Nc3 & 250 & 350 & Ethanol (7) & $1: 50$ & Hot air oven & a \\
\hline Nc4 & 250 & 400 & Methanol (8) & $1: 50$ & Hot air oven & a \\
\hline Nc5 & 250 & 200 & Acetone (4) & $1: 50$ & $\begin{array}{c}\text { Rotary } \\
\text { evaporation }\end{array}$ & $\mathrm{b}$ \\
\hline Nc6 & 250 & 400 & Acetonitrile (8) & $1: 50$ & $\begin{array}{c}\text { Rotary } \\
\text { evaporation }\end{array}$ & $\mathrm{b}$ \\
\hline Nc7 & 250 & 350 & Ethanol (7) & $1: 50$ & $\begin{array}{c}\text { Rotary } \\
\text { evaporation }\end{array}$ & $\mathrm{b}$ \\
\hline Nc8 & 250 & 400 & Methanol (8) & $1: 50$ & $\begin{array}{c}\text { Rotary } \\
\text { evaporation }\end{array}$ & $\mathrm{b}$ \\
\hline
\end{tabular}

$* a=90^{\circ} \mathrm{C}$ and $\mathrm{b}=60^{\circ} \mathrm{C}$ 


\begin{tabular}{|c|c|c|c|c|c|c|}
\hline \multicolumn{7}{|c|}{ Table 2: Composition Of Silymarin phytosome Formulations. } \\
\hline Formula & Silymarin (Mg) & Lecithin (Mg) & Stoichiometry & Method & Evaporation & $\begin{array}{c}\text { Evaporation } \\
\text { Temp. }\left({ }^{\circ} \text { C) }\right.\end{array}$ \\
\hline Ph1 & 482.4 & 750 & $1: 1$ & Physical Mixing & Hot Air Oven & a \\
\hline Ph2 & 482.4 & 750 & $1: 1$ & Co-Grinding & Hot Air Oven & a \\
\hline Ph3 & 482.4 & 750 & $1: 1$ & Physical Mixing & Rot. Evap. & b \\
\hline Ph4 & 482.4 & 750 & $1: 1$ & Co Grinding & Rot. Evap. & b \\
\hline Ph5 & 482.4 & 1125 & $1: 1.5$ & Physical Mixing & Hot Air Oven & a \\
\hline Ph6 & 482.4 & 1125 & $1: 1.5$ & Co-Grinding & Hot Air Oven & a \\
\hline Ph7 & 482.4 & 1125 & $1: 1.5$ & Physical Mixing & Rot. Evap. & b \\
\hline Ph8 & 482.4 & 1125 & $1: 1.5$ & Co-Grinding & Rot. Evap. & b \\
\hline Ph9 & 482.4 & 1500 & $1: 2$ & Physical Mixing & Hot Air Oven & a \\
\hline Ph10 & 482.4 & 1500 & $1: 2$ & Co-Grinding & Hot Air Oven & a \\
\hline Ph11 & 482.4 & 1500 & $1: 2$ & Physical Mixing & Rot. Evap. & b \\
\hline Ph12 & 482.4 & 1500 & $1: 2$ & Co-Grinding & Rot. Evap. & b \\
\hline
\end{tabular}

$* A=80^{\circ} \mathrm{C}$ And $\mathrm{B}=40^{\circ} \mathrm{C}$.

method followed by evaporation either in hot air oven or under vacuum. In the first approach, phytosomes were prepared using $482.4 \mathrm{mg}(1 \mathrm{mM})$ Silymarin placed in $250 \mathrm{~mL}$ rounded flask and an equivalent amount $750 \mathrm{mg}(1 \mathrm{mM})$ of lecithin with varying molar ratios (1:1, 1:1.5 and 1:2). Then solvents were added in different ratio. The flask was stirred using magnetic stirrer for 30 minutes and placed under reflux at $40^{\circ} \mathrm{C}$ for $24 \mathrm{hrs}$. The remaining solvent was evaporated under vacuum then the precipitate was scratched and collected for further chemical and physical inspection. ${ }^{7,28}$

In the second approach, phytosomes were prepared by first placing $482.4 \mathrm{mg}$ of Silymarin with the calculated amounts of lecithin (Table 2) in a porcelain mortar and pestle and co-grinding was continued for $30 \mathrm{~min}$. The collected powder was then dissolved in a mixture of $90 \mathrm{~mL}$ anhydrous ethanol and $40 \mathrm{~mL}$ acetone. Stirring and reflux were then continued at $40^{\circ} \mathrm{C}$ for $24 \mathrm{hrs}$. The remaining solvent was evaporated under vacuum then the precipitate was scratched and collected for further chemical and physical inspection as mentioned above. ${ }^{28-30}$

\section{Morphological characterizations}

The morphology of the prepared formulations was examined using scanning electron microscope (JEOLJSM-5400, JEOL Ltd. Tokyo, Japan). ${ }^{7}$ Few particles of powder were precisely fixed to aluminum stubs using double- sided adhesive carbon discs and then were made electrically conductive by coating with gold sputter under vacuum (SPI-Module Sputter Coater, SPI Supplies Inc., USA). Transmission Electron Microscope (TEM-JEOL-JSM-5400 JEOL Ltd. Tokyo, Japan) was also used to detect particles morphology in suspension form. One drop of the resultant complex dispersions was placed onto a carbon-coated copper grid, leaving a thin liquid film. The air-dried films were then stained and viewed under the transmission electron microscope. . $^{2,14}$

\section{Evaluation of average particle size}

Average particle size and size distribution of the prepared formulations were determined by the dynamic light scattering (DLS) technique (PSS-NICOMP 380-ZLS, USA). Before measurements, the samples were diluted to 10 times its original volume with de-ionized water. Samples of $250 \mu \mathrm{L}$ suspensions were transferred to a disposable low volume cuvette. Samples were left to equilibrate to a temperature of $25^{\circ} \mathrm{C}$ for 2 minutes. Then the analysis was performed using five measurements in 12 runs of 10 seconds each. ${ }^{2,7,26}$

\section{Differential scanning calorimetry (DSC)}

Samples of $5 \mathrm{mg}$ of the individual formulations (nanocrystals and phytosome) and the drug were filled into tightly sealed aluminum flat- bottomed pans and heated in DSC-60 instrument (Shimadzu, Japan) in an atmosphere of nitrogen to eliminate the oxidative and paralytic effects. The range of heating temperatures was set between $0-300^{\circ} \mathrm{C}$ which exceeds the melting points of all used materials and the heating rate was kept at $5^{\circ} \mathrm{C} / \mathrm{min}$.,31 The obtained thermo grams were evaluated for any interactions or possible changes in the thermal behavior of the samples.

\section{Fourier Transform -Infrared Spectroscopy (FT-IR)}

Samples of Silymarin pure and the prepared nanoparticles were diluted with potassium bromide in the ratio of 1:10 and after drying at room temperature they 
were compressed to form discs. The discs were later subjected to FT-IR spectroscopy measurements using a JASCO FT-IR -3600 spectrometers (Easton, USA). Data was collected at a resolution of $4 \mathrm{~cm}^{-1}$ in a wave number region of $400 \mathrm{~cm}^{-1}$ to $4000 \mathrm{~cm}^{-1} \cdot 14,7$

\section{X-ray Diffraction (XRD)}

Pure silymarin and samples of the prepared nanocrystals and phytosomes, were examined using Shimadzu XRD -6000 (X-Ray Diffract meter SERIAL NO. Q30344700643CZ, Tokyo, JAPAN). The measurements were carried out using $\mathrm{Cu}$ as an anode material and operated at a voltage of $25 \mathrm{KV}$ with a current of $40 \mathrm{~mA}$. The samples were analyzed in the 2 Theta angle range of 4 to 50 degrees and a scanning speed of 1.2degree/ $\min ^{26-27}$

\section{Solubility, drug content and in-vitro dissolution studies}

Powder samples of the prepared formulations equivalent to $5 \mathrm{mg}$ Silymarin were taken and then dissolved in $50 \mathrm{~mL}$ solvent system composed of methanol-water (75:25). Samples of $0.1 \mathrm{~mL}$ were then placed in $10 \mathrm{~mL}$ volumetric flasks and completed to $10 \mathrm{~mL}$ using the previous system. Spectrophotometric analysis was carried out at $288 \mathrm{~nm}$. The concentration of Silymarin in each formulation was determined after the construction of a calibration curve of Silymarin in the same each formulation was calculated.

The solubility of Silymarin from the prepared nanocrystals and phytosomes formulations were determined using UV-Visible spectroscopy (JASCO- model V- 560, Japan). ${ }^{14}$ Samples from each formulation equivalent to $5 \mathrm{mg}$ Silymarin were dissolved in $50 \mathrm{~mL}$ methanol-water (75:25) then serial dilutions of $0.1,0.2,0.3,0.4$ and 0.5 were completed to $10 \mathrm{~mL}$ from the solvent system composed of methanol-water (75:25). The samples were measured at $288 \mathrm{~nm}$ for comparing differences in the solubility between the prepared nanocrystals and phytosomes to that of pure Silymarin. ${ }^{32}$

The in-vitro release studies were carried out on nanocrystals and phytosomes using a dissolution test analyzer (RC-3B, Tianjin Instrument Company, China). The powder (containing $5 \mathrm{mg}$ formula) was added to $250 \mathrm{~mL}$ of dissolution medium (0.1N HCL) and the instrument was operated at a paddle speed of $100 \mathrm{rpm}$ at $37^{\circ} \mathrm{C}^{33}$ At definite time intervals, $5 \mathrm{~mL}$ dispersion samples were withdrawn out and the fresh dissolution medium was placed to maintain constant volume $(250 \mathrm{ml})$. The samples were centrifuged, filtered and measured spectrophotometry at $288 \mathrm{~nm}$ to determine the percentage of silymarin dissolved.

\section{Sterility testing after exposing to gamma radiation}

Each of NC6 and PH1 formulation was separately filled into $2 \mathrm{ml}$ ampoules (under air). The ampoules in small boxes were sterilized by Cobalt-60 as a source of gamma radiation at ambient temperature using Indian Gamma Cell. At National Center for Radiation Research and Technology (NCRRT) Cairo, Egypt. (Dose rate $=1678.98 \mathrm{~Gy} / \mathrm{h}$ ), at the time of experiments.

In this test, two gamma radiation doses were attempted for sterilization, viz., $15 \mathrm{kGy}$ and $25 \mathrm{kGy}$. Two formulation ampoules were exposed to Gamma radiation, while another two ampoules were left non-irradiated as control. The irradiated samples were examined underusing SEM, XRD and FT-IR to determine the solid state stability of the formulations after irradiation. ${ }^{18-20}$

For sterility testing, the total plate count (TPC) determination was performed according to a reported method. ${ }^{34-35}$ In this method, $250 \mathrm{mg}$ Silymarin powder was added to $25 \mathrm{~mL}$ of sterilized saline solution, (1:10 dilution). The mixture was homogenized and then gradually diluted to $10^{-2}, 10^{-3}, 10^{-4}$, and $10^{-5}$. A sample of $1 \mathrm{~mL}$ was poured into a sterile Petri dish then $15-20 \mathrm{~mL}$ of nutrient agar medium was added, shaken gently until evenly mixed and left until gelled. The Petri dish was reversed and incubated at $30^{\circ} \mathrm{C}$ for $48 \mathrm{~h}$. The number of bacteria was calculated by multiplying average number of colonies by the dilution factor.

Determination of the number of mold and yeast was also performed according to the method mentioned above. ${ }^{36}$ However, in this method, $15-20 \mathrm{ml}$ of potato dextrose agar medium was poured onto $1 \mathrm{~mL}$ sample and the sterile Petri dish was shaken gently until evenly mixed, gelled and incubated at $20-24^{\circ} \mathrm{C}$ for 5 days. The numbers of mold and yeast were calculated by multiplying the average number of colonies by the dilution factor.

\section{RESULTS AND DISCUSSION}

\section{Particle size and morphological characterizations}

The morphology of the nanocrystals and phytosome formulations are demonstrated from SEM and TEM

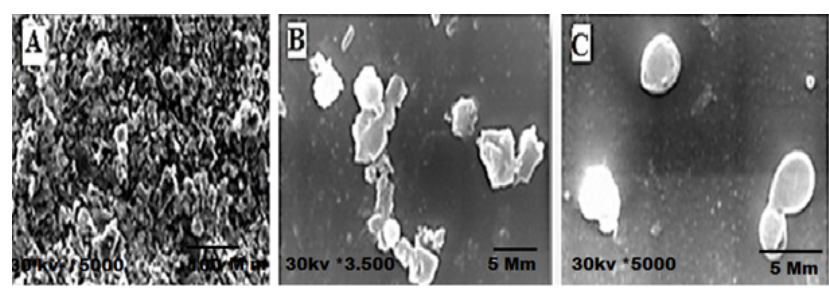

Figure 1: (SEM) of Silymarin powder (A)Nanocrystals(B) and Phytosomes (C) 


\begin{tabular}{|c|c|c|c|}
\hline \multicolumn{4}{|c|}{ Table 3 The particle size distribution of silymarin } \\
Nanocrystals and phytosomes determined by DLS. \\
\hline Formula & $\begin{array}{c}\text { Particle size } \\
\text { distribution }\end{array}$ & Formula & $\begin{array}{c}\text { Particle size } \\
\text { distribution }\end{array}$ \\
\hline Ncy1 & 11.9 & Phy3 & 88.0 \\
\hline Ncy2 & 11.7 & Phy4 & 151.0 \\
\hline Ncy3 & 11.2 & Phy5 & 159.1 \\
\hline Ncy4 & 49.4 & Phy6 & 104.4 \\
\hline Ncy5 & 31.7 & Phy7 & 123.3 \\
\hline Ncy6 & 31.9 & Phy8 & 252.6 \\
\hline Ncy7 & 95.6 & Phy9 & 752.0 \\
\hline Ncy8 & 99.5 & Phy10 & 891.7 \\
\hline Phy1 & 186.7 & Phy11 & 891.1 \\
\hline Phy2 & 71.3 & Phy12 & 904.0 \\
\hline
\end{tabular}

micrographs in Figure 1 and 2. It was found that Silymarin nanocrystals prepared from acetone, acetonitrile and ethanol were smaller in size than those prepared from methanol and more uniform in shape, which is in line with its different solubility in these liquids. ${ }^{36-37}$ The average particle size $(\mathrm{nm})$ of nanocrystals and phytosomes measured using DLS are demonstrated in Table 3, Figure 3.

\section{Differential scanning calorimetry (DSC)}

The DSC thermo grams of the bulk silymarin, Nano crystal and phytosome formulations are illustrated in Figure 4. The bulk silymarin showed a sharp melting endotherm at $159^{\circ} \mathrm{C}$ (Figure 4). The DSC melting temperature of silymarin is similar to that reported in the literature $\left(158^{\circ} \mathrm{C}\right)$ that suggest high content of silybinin in the bulk powder of silymarin. The Nano crystal formulation showed broad endotherms representing semi crystalline phases where the initial melting endotherm was observed around $85-90^{\circ} \mathrm{C}$ that may represent evaporation of remaining solvents (Ncy2 and Ncy6 in Figure 5). The second main melting endotherm was observed at $150-152^{\circ} \mathrm{C}$ that is slightly lower than the melting peak reported for silymarin in the literature that may due to plasticizing effect of remaining solvent and effects of size reduction to the Nanorange. ${ }^{30}$

The melting endotherm of lecithin demonstrated a melting peak at $124^{\circ} \mathrm{C}$ (Figure 5). The melting endotherms observed for phytosomes were short and broad which represent amorphous composites. The degree of broadness of the endotherm, increased with the increased proportion of lecithin (Molar ratio) in the mixture as demonstrated by Phy1 (1:1), Phy6 (1:1.5) and Phy11 (1:2) of Silymarin to lecithin. It was also found that no marked differences in DSC were observed for phytosomes prepared by physical mixing or co-grinding.

\section{Fourier Transform Infra-Red Spectroscopy (FT-IR)}

The FT-IR spectra of the samples are shown in Figure 6. Silymarin showed characteristic peaks for $-\mathrm{OH}$, - $\mathrm{CH}$ stretching at 2900 to $3400 \mathrm{~cm}^{-1}$, C-C stretching and $\mathrm{C}=\mathrm{O}$ stretching in the region $1000-1700 \mathrm{~cm}^{-1}$ which was retained in all nanocrystal formulations (Fig. 6 A,B,C and D).

Phytosomes and physical mixtures showed FT- IR pattern similar to that of lecithin (Fig. 6) with complete disappearance of the characteristic peaks of Silymarin between 1000 and $1700 \mathrm{~cm}^{-1}$ suggesting formation of new composite. In the FT-IR spectrum of PH11(Fig 6), a new peak appeared at $2999 \mathrm{~cm}^{-1}$ which may indicate $\mathrm{H}$-bonding formation between the $\mathrm{C}=\mathrm{O}$ groups of lecithin and the free $\mathrm{OH}$ groups of Silymarin and disappearance of peaks at $1705 \mathrm{~cm}^{-1}$ (C- O stretching) indicating also formation of a new coamorphous phase.

\section{$\mathrm{X}$ ray Diffraction $(\mathrm{XRD})$}

The solid states of the drug and the prepared nanocrystals as well as the phytosomes Silymarin demonstrated sharp diffraction lines in the 2 Theta region 5-20 indicating its crystalline state (Figure 7), most nanocrystals retained their crystalline structure (Ncy2 and Ncy4) while Ncy6 (Figure 7) showed too short diffraction lines at the previous region which indicates a semicrystalline state. In Figure 7; lecithin demonstrated a very short diffraction pattern indicating its amorphous nature and also the prepared phytosomes (Figure 7) showed a characteristic amorphous halo in the 2 Theta regions 5-20 which indicated complete dissolution of the crystalline silymarin into the amorphous lecithin forming a completely amorphous composite.

\section{Solubility, drug content and in-vitro dissolution}

The results of water solubility, content of Silymarin in each Nano crystal and phytosome formulation are summarized in Table 4. The Nano crystal formulations showed higher percentage of drug content compared to phytosomes which might be due to partial loss of the drug during physical mixing and/or co-grinding and also to different relative solubility of the drug and lecithin in the used solvents. The Nano crystal Ncy6 demonstrated more than 8 folds increase in solubility $(17.10 \%)$ compared to pure bulk Silymarin $(2.10 \%)$. This formula was prepared using fast evaporation of 
acetonitrile solution using rotary evaporation at $60^{\circ} \mathrm{C}$, while Nano crystal Ncy1 (solubility $15.2 \%$ ) was prepared from acetone using evaporation in hot air oven at $90^{\circ} \mathrm{C}$.

Phytosomes enhanced the solubility of pure drug more than nanocrystals, where formula PH-1 (molar ratio 1:1) demonstrated more than 13 folds increase in solubility of Silymarin. When the molar ratio of drug to lecithin was increased to $1: 2$, the solubility was increased to $35.6 \%$ with more than 17.5 folds as demonstrated by PH-11. It was also noticed that phytosomes prepared using physical mixing resulted in higher Percentage solubility than those prepared by co-grinding. The results of solubility of phytosomes which converted the crystalline Silymarin to the amorphous form are consistent with the data reported in the literature. ${ }^{38-42}$ It is well known that the amorphous materials do not have long-range order of molecules such as the crystal lattice found in crystalline materials. ${ }^{42}$ The amorphous state also has higher internal energy, larger free volume, and greater molecular mobility and thus their solubility is much higher. ${ }^{43}$ However, the amorphous structure is metastable with respect to crys-
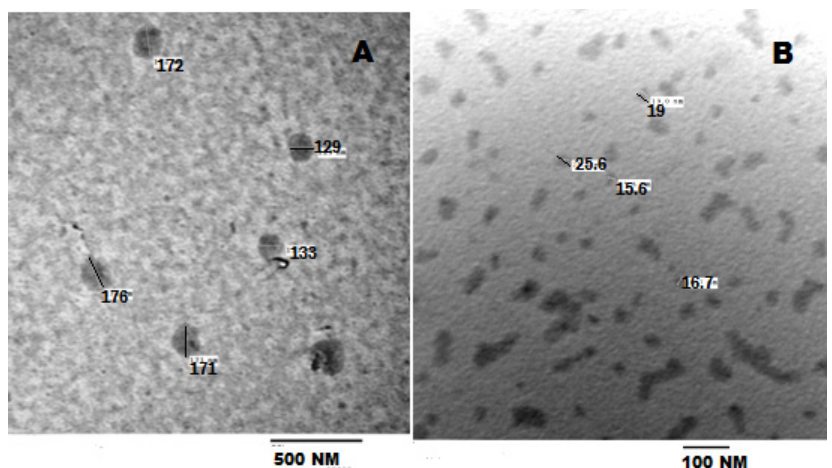

Figure 2: (TEM) Transmission electron micrographs (A) Nanocrystal Ncy6 (B) Phytosome Phy1 talline state, and has a tendency to be spontaneously converted into a crystalline state of lower energy. ${ }^{42}$ The presence of lecithin in high proportion with Silymarin might help retardation of the changes in the amorphous state by the intermolecular H-bonding and coamorphous composite formation.

The results of in-vitro dissolution are shown in Figure 8. As the in-vitro dissolution of poorly water-soluble drugs, especially in the stander biopharmaceutical classification system (BCS) class II drugs, is proportional to the oral absorption, evaluation of in-vitro dissolution was conducted to predict the in-vivo performance. In addition, dissolution under non-sink conditions is a better way to evaluate the quality of a drug formulation. ${ }^{31-32}$ Thus, testing the in-vitro dissolution behavior of nanocrystals, phytosomes compared to Silymarin bulk powder and a marketed Silymarin tablet was conducted under non-sink conditions.

As shown in Figure 8 it was found that Nano crystal NC6 and phytosome Phy 1 exhibited much faster and higher dissolution profiles than Silymarin powder and the reference formulation. The maximum release of
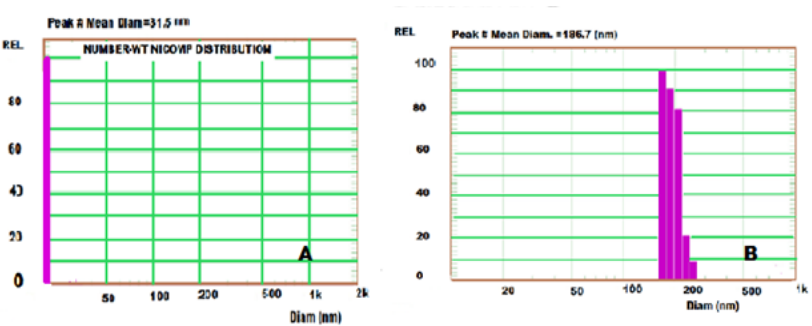

Figure 3: grah from DLS show (A)Nanocrystal Ncy6mean diameter $=31.5 \mathrm{~nm}$, (B)Phytosome Phy1mean diameter= $196.7 \mathrm{~nm}$.

Table 4: Drug content and solubility (\%) of silymarin from bulk powder, nanocrystals and phytosomes.

\begin{tabular}{|c|c|c|c|c|c|}
\hline Formula & $\begin{array}{c}\text { Drug content } \\
(\mathbf{\%})\end{array}$ & $\begin{array}{c}\text { Solubility } \\
(\mathbf{\%})\end{array}$ & Formula & $\begin{array}{c}\text { Drug content } \\
(\%)\end{array}$ & Solubility (\%) \\
\hline Silymarin & 100.00 & 2.10 & - & - & - \\
\hline NCy1 & 87.40 & 15.20 & Phy3 & 77.80 & 6.88 \\
\hline NCy2 & 93.60 & 9.00 & Phy4 & 47.40 & 24.58 \\
\hline NCy3 & 92.50 & 14.20 & Phy5 & 46.60 & 11.54 \\
\hline NCy4 & 80.40 & 10.80 & Phy6 & 33.00 & 10.26 \\
\hline NCy5 & 87.40 & 11.50 & Phy7 & 46.60 & 8.33 \\
\hline NCy6 & 93.60 & 17.10 & Phy8 & 33.00 & 8.98 \\
\hline NCy7 & 92.50 & 12.70 & Phy9 & 40.00 & 7.90 \\
\hline NCy8 & 80.40 & 10.60 & Phy10 & 35.00 & 17.39 \\
\hline Phy1 & 77.80 & 27.00 & Phy11 & 40.00 & 35.59 \\
\hline Phy2 & 47.4 & 13.8 & Phy12 & 35.0 & 22.14 \\
\hline
\end{tabular}




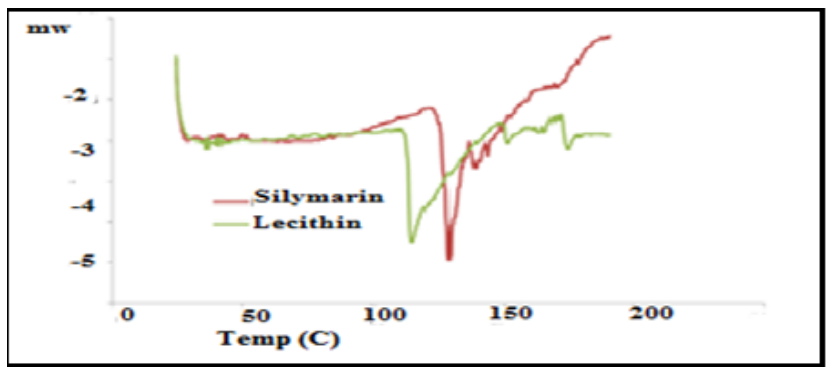

Figure 4: DSC graph of silymarin and lecithin

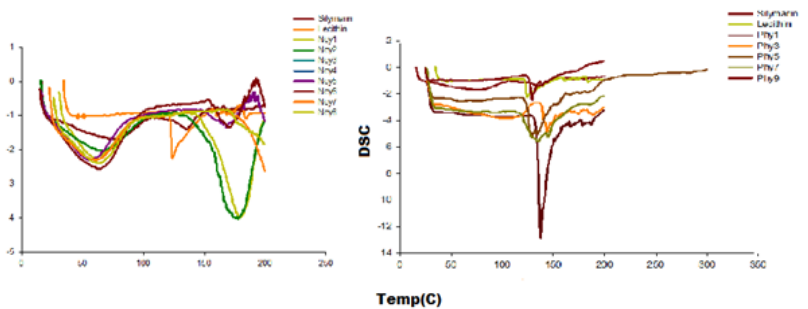

Figure 5: DSC graph (A)Nano crystal formula (B)phytosome formula.
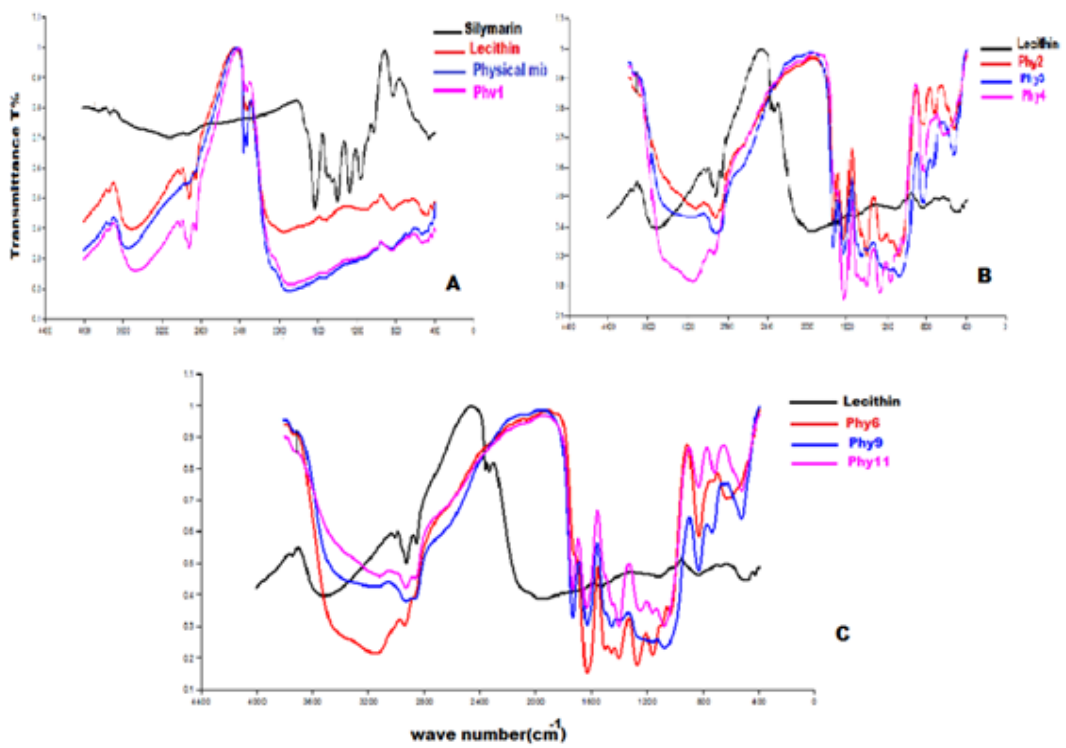

Figure 6: FT- IR spectra of (A) Silymarin; Lecithin; physical mixture and phytosme (Phy1),(B) spectra of phytosme (Phy2),(phy3) and (ph4) and (C) spectra of phytosme (Phy6),(phy9) and (ph11).

Table 5: Evaluation of solubility of Silymarin from NCy6 and Phy11 before and after gamma
\begin{tabular}{|c|c|c|c|c|c|c|}
\hline $\begin{array}{c}\text { Irradiation } \\
\text { dose }\end{array}$ & Formula & $\begin{array}{c}\text { Mass } \\
(\mathbf{m g})\end{array}$ & $\begin{array}{c}\text { Theoretical } \\
\text { content }(\mathbf{m g})\end{array}$ & $\begin{array}{c}\text { Theoretical } \\
\text { concentration } \\
(\mathbf{m c g} / \mathrm{mL})\end{array}$ & $\begin{array}{c}\text { Practical } \\
\text { concentration } \\
(\mathbf{m c g} / \mathrm{mL})\end{array}$ & $\begin{array}{c}\% \\
\text { dissolved }\end{array}$ \\
\hline Un-irradiated & NCy6 & 5.00 & 4.68 & 9.36 & 1.60 & 17.12 \\
\hline $15 \mathrm{kGy}$ & NCy6 & 5.00 & 4.68 & 9.36 & 1.19 & 12.70 \\
\hline $25 \mathrm{kGy}$ & NCy6 & 5.00 & 4.68 & 9.36 & 0.68 & 7.31 \\
\hline Un-irradiated & Phy1 & 4.90 & 1.96 & 3.92 & 1.39 & 35.59 \\
\hline $15 \mathrm{kGy}$ & Phy1 & 4.90 & 1.96 & 3.92 & 1.15 & 29.33 \\
\hline $25 \mathrm{kGy}$ & Phy1 & 4.90 & 1.96 & 3.92 & 0.95 & 24.23 \\
\hline
\end{tabular}

Silymarin from the phytosome Phy1 was 1.8 after 90 min followed by Nano crystal Ncy6 2 which resulted in 2 fold release compared to bulk powder and respectively.

\section{Sterilization using gamma radiation}

The results of sterility of irradiated Nano crystal NC6 and phytosome Phy11 showed that there was no micro- bial bio burden in $25 \mathrm{kGy}$ irradiated groups, indicating that the samples were sterilized. On the other hand, microbial bio burden were founded in the two positive control groups (non-irradiated).

The number of colonies was found to be $23 \times 10^{2} \mathrm{cfu}$ and $11.31 \times 10^{2} \mathrm{cfu}$ grown before and after gamma irradiation with $15 \mathrm{kGy}$ for the Nano crystals group and 


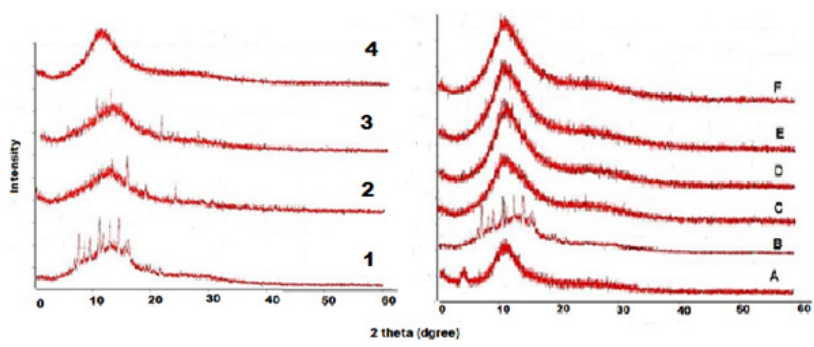

Figure 7: XRD spectra of 1) Silymarin; 2) nanocrystals Ncy2; 3) nanocrystal Ncy4 and 4) nanocrystal Ncy6.

A) Lecithin; B) Silymarin and phytosomes: C) Phy-1; D) Phy3; E) Phy-6 and F) Phy-11

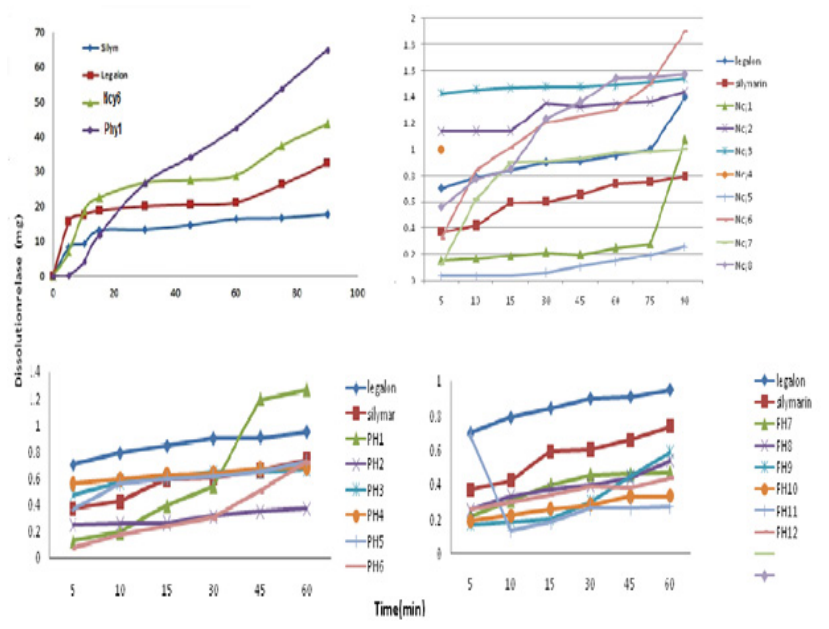

Figure 8: In-vitro dissolution graph

$43 \times 10^{2} \mathrm{cfu}$ and $31 \times 10^{2} \mathrm{cfu}$ for phytosomes, respectively with no fungus contamination detected in all samples. Whilst no growth was observed at dose $25 \mathrm{kGy}$ that is the dose known to stop viability of such microorganisms. These results indicate that the irradiation dose of $25 \mathrm{kGy}$ is the optimum sterilization dose for Nano crystal and phytosome formulations, and it is the sufficient dose for complete radiation sterilization of the product.

\section{Effects of radiation on the solid state}

The XRD of the prepared formulation was repeated after irradiation and the results indicated that the semicrystalline shape of Nanocrystal (Ncy6) changed to highly crystalline after both $15 \mathrm{kGyand} 25 \mathrm{kGy}$ (Figure 9).

For the phytosome (Phy11) the solid state also changed from completely amorphous to partially crystalline (Figure 10) that could affect the solubility parameter.

The FT-IR results obtained after irradiation also indicated dramatic changes in in the solid state IR pattern of $\mathrm{NCy} 6$ that showed elongation of the peaks between $1000 \mathrm{~cm}^{-1}$ and $1700 \mathrm{~cm}^{-1}$ and disappearance of the broad peaks in the region 2500-3000 $\mathrm{cm}^{-1}$ (Figure 9). For phytosomes there was no difference between the

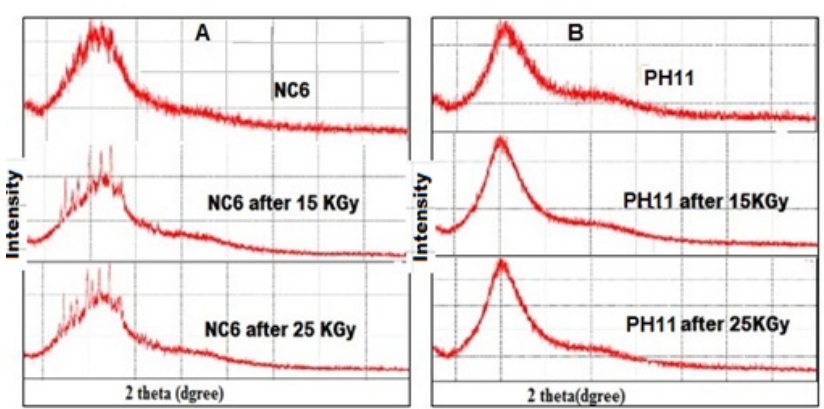

Figure 9: XRDPatterns of NCy6 (A) and Phy1 (B) formulations, before and after exposure to 15 and $25 \mathrm{~K}$ Gry of gamma radiation.
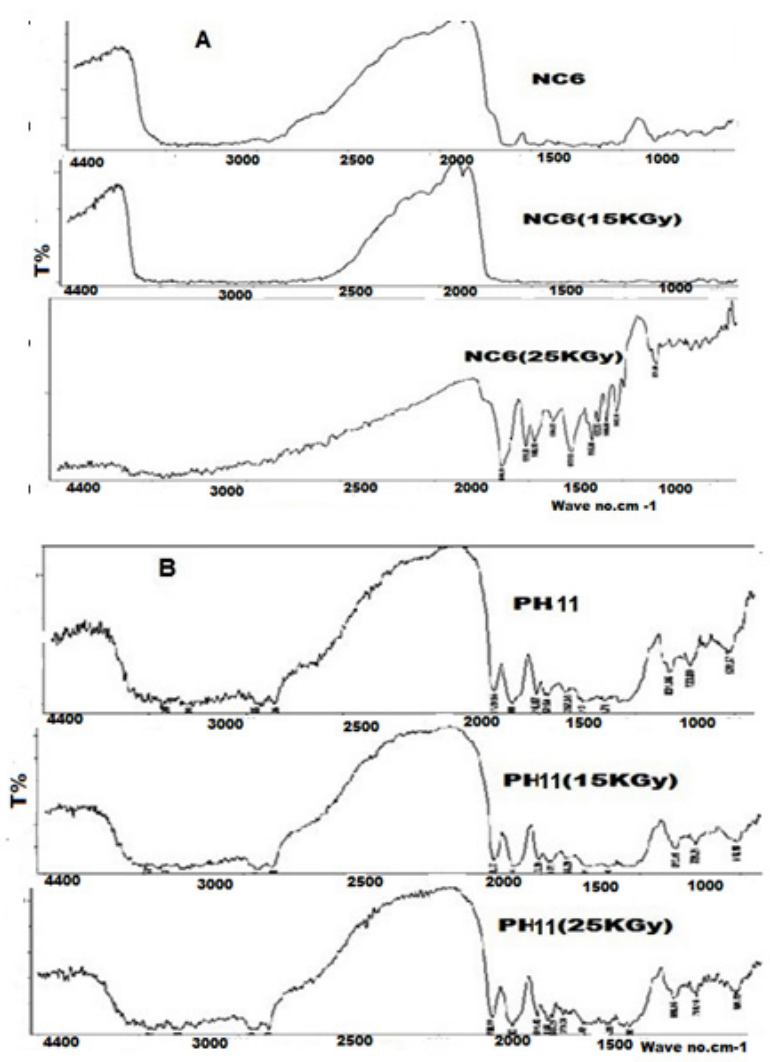

Figure 10: FT-IR of NCy6 (A) and Phy11 (B) formulations, before and after exposure to15 kGy and 25 kGy of gamma radiation

FT-IR patterns obtained for Phy11 before and after irradiation (Figure 10).

\section{Effects of radiation on solubility}

The amount of Silymarin dissolved before and after gamma irradiation was evaluated to determine the effects of radiation on solid state and as consequence on solubility. The results in Table 5 showed that the solubility of nanocrystal NCy6 decreased by $25.82 \%$ and $57.30 \%$ after gamma irradiation with $15 \mathrm{kGy}$ and 25 
$\mathrm{kGy}$, respectively. However, the solubility of phytosome Phy11 was also decreased only by $17.60 \%$ and $31.92 \%$ after irradiation with $15 \mathrm{kGy}$ and $25 \mathrm{kGy}$, respectively. These results may suggest that the phytosome formulations managed to withstand the irradiation sterilization with $25 \mathrm{kGy}$ more than nanocrystals with lesser effects on solubility of Silymarin

\section{CONCLUSION}

Nanocrystals and phytosomes were shown to be successful in enhancing the physicochemical properties of silymarin. The DSC, IR and XRD data also confirmed retaining the crystalline state of nanocrystals and the amorphous state of phytosomes. The increased solubility could be employed in oral and/or parenteral dosage forms to increase the bioavailability of Silymarin. The increased dissolution rate compared to marketed products is another proof of success for such promising new formulations. The process of sterilization using gamma radiation should be used carefully with semi crystalline or amorphous drug formulations to enable control of undesirable effects on solubility due to changes in the solid state. Therefore, nanocrystals and phytosomes could be considered valuable alternative approaches for overcoming problems of low solubility and bioavailability of Silymarin.

\section{ACKNOWLEDGEMENT}

The authors would like to thank the Nanotechnology Research Unit (P.I. Prof. Dr. Ahmed I. El-Batal), Drug Microbiology Lab., Drug Radiation Research Department, NCRRT, Egypt, for financing and supporting this study under the project "Nutraceuticals and Functional Foods Production by using Nano/ Biotechnological and Irradiation Processes" and Faculty of the Pharmacy Beni-suef University.

\section{CONFLICT OF INTEREST}

Authors have declared that no competing interests exist.

\section{ABBREVIATION}

DLS: Dynamic light scattering; FT-IR: Fourier Trans- form Infrared; XRD: $\mathrm{X}$ ray Diffraction; DSC: Differential scanning calorimetry; TEM: Transmission electron micrographs; SEM: Scanning electron micrographs.

\section{REFERENCES}

1. Jain KK. Drug Delivery Systems. Methods in Molecular Biology. 2008;437.

2. El-Ridy MS, Abd-Elhameed A, El-Shamy A, Ramadan, Rehab F, AbdelRahman, et al. Liposomal Encapsulation of Amikacin Sulphate for Optimizing
Its Efficacy and Safety. British Journal of Pharmaceutical Research. 2015; 5(2):98-116

3. Bouqute W, Ceelen W, Fritzinger B, Paattyn P, Peters M, Remon JP, et al. Paclitaxel/B-cyclodextrincomplexs for hyperthermic peritoneal perfusionformulation and stability. Eur J pharm Biopharm. 2007;66(3):391-7.

4. Chen H, Tang L, Qin Y, Yin Y, Tang J, Tang W, et al. Lactoferrin-modified procationic liposomes as a novel drug carrier for brain delivery. Eur $\mathrm{J}$ Pharm Biopharm. 2010;40(2):94-102.

5. Gullotti E, Yeo Y. Beyond the imaging: limitations of cellular uptake study in the evaluation of nanoparticles. J Control Release. 2012;164(2):170-6.

6. Shao K, Huang R, Li J, Han L, Ye L, Lou J, et al. Angiopep-2 modified PEPEG based polymeric micelles for amphotericin $B$ delivery targeted to the brain. J Control Release 2010;147(1):118-26.

7. Kavitha KS, Syed Baker, Rakshith D, Kavitha HU, Yashwantha Rao HC, Harini BP, et al. Plants as Green Source towards Synthesis of Nanoparticles. International ResearchJournal of Biological Sciences June. 2013;2(6):66-76.

8. Jens-Uwe AH, Müller RH. Nano crystal technology, drug delivery and clinical applications. International Journal of Nano medicine. 2008;3(3)295-309.

9. Shackleford DM, Faassen WA, Houwing N, Lass H, Edwards GA, Porter CJ, et al. Contribution of lymphatically transported testosterone undecanoate to the systemic exposure of testosterone after oral administration of two andriol formulations in conscious lymph duct-cannulated dogs. J Pharmacol Exp Ther. 2003;306(3):925-33.

10. El-Batal Al, Roquia Al-Habib. Elevated yield of lovastatin by Monascuspurpureus from date wastes extract and encapsulation in nanoparticles. International Journal of Pharmaceutical Science and Health Care. December. 2012;6(2):62-83.

11. El-Ridy MS, El-Shamy AE, Ramadan A, Abdel-Rahman RF, Awad GA, El-Batal A, et al. Mohsen and Asmaa B. Darwish. Liposomal Encapsulation of Amikacin Sulphate for Optimizing Its Efficacy and Safety British Journal of Pharmaceutical Research. 2015;5(2):98-116.

12. Vijaykumar Nekkanti, Venkateswarlu Vabalaboin, RavirajPillai. Drug Nanoparticles. Nanotechnology and nanomaterial INTECH. 2012. chapter6.

13. SaonereSuryawanshi JS. Phytosome: An emerging trend in herbal drug treatment. Journal of Medical Genetics and Genomics. August. 2011;3(6):109-14.

14. Libo Wu, Zhang J, Watanabe W. Physical and chemical stability of drug nanoparticles. Advanced Drug Delivary Reviews. 2011;63(6):456-69.

15. Giacomelli S, Gallo D, Apollonio P, Ferlini C, Distefano M, Morazzoni P, et al. Silybin and its bioavailable phospholipid complex (IdB 1016) potentiate in vitro and in vivo activity of cisplatin. Life Sci. 2002;70(12):1447-59.

16. Fraschini F, Demartini G, Esposti D. Pharmacology of Silymarin. Clin Drug Invest. 2002;22(1):51-65.

17. Canman CE, Lim DS, Cimprich KA, Taya Y, Tamai K, Sakaguchi K, et al. Activation of the ATM kinase by ionizing radiation and phosphorylation of p53. Science. 1998;281(5383):1677-9.

18. El-Ridy MS, Abdelbary A, Nasr EA, Khalil RM, Mostafa DM, El-Batal AI, et al. Niosomal Encapsulation of the Anti-tubercular Drug Pyrazinamide. Drug Development and IndustrialPharmacy. 2011;37(9):1110-8.

19. Parisi AN, Antoine AD. Characterization of Bacillus pumilusE601 Spores after Single Sublethal Gamma Irradiation Treatments, Applied Microbiology. 1975;29(1):34-9.

20. DN Zou, DR Zhang, XH Zhou. HPLC determination of entrapment efficiency of Matrine-loaded albumin nanoparticles. Chin J Pharm Anal. 2008;28(1):93-6.

21. Polyak SJ, Morishima C, Lohmannd V, Pala S, Leee DY, Liue Y, et al. Identification of hepatoprotective flavonolignans from silymarin, PNAS. 2010;107(13):5995-9.

22. Giacomelli S, Gallo D, Apollonio P, Ferlini C, Distefano M, Morazzoni P, et al. Silybin and its bioavailable phospholipid complex (IdB 1016) potentiate in vitro and in vivo activity of cisplatin. Life Sci. 2002;70(12):1447-59.

23. Madaus R, Halbach $G$, Trost W. Salt of silymarin group with aminopolyhydroxy alcohols. United States patent US. 1976;3:994-5.

24. Das S, Partharoy, Auddy R, Mukherjee A. Silymarin nanoparticle prevents Paracetamol-induced hepatotoxicity. International Journal of Nanomedicine Gune. 2011;6:1291.

25. Wachter $\mathrm{W}$, Zaeske $\mathrm{H}$. Process for the manufacture of flavanolignan preparation with improved release and absorbability, compositions obtainable thereby and their use for the preparation of pharmaceuticals. 2000;60:203-84. 
26. Junyapraserta VB, Morakul B. Nanocrystals for enhancement of oralbioavailability of poorly water-soluble drugs. Asian journal of pharmaceutical sciences. 2015;10(1):13-23.

27. Nanjwade BK, Derkar GK, Bechra HM, Nanjwade VK, Manvi FV. Design Characterization of Nanocrystals of Lovastatin for Solubility and Dissolution Enhancement. Journal of Nanomedicine and Nanotechnology. 2011;2:107.

28. Sindhumol PG, Thomasi M, Mohanachndran PS. A Novel dosage from for enhancement of Bioavailability of botanicals and Neutraceuticals. International Journal of Pharmacy and Pharmaceutical Sciences. 2010;(2)4:10-4.

29. Rathore P, Swami G. Planterosomes Apotentialphyto-phosspholipid carriers for the bioavailabilty enhancement of herbal extracts. International Journal of Pharmaceutical Sciences and Research. 2012;3(3):737-55. polyphenolics interactions: The PHYTOSOME $®$ strategy to improve the bioavailability of phytochemicals Fitoterapia. November. 2009;81(5):306-14

31. Sharma S, Roy RK. PHYTOSOMES AN EMERGING TECHNOLOGY1. International Journal of Pharma Research and Development. 2010;2(5)1-7.

32. Wei Wu, Wang Y, Li Qu. European journal of pharmaceutics Enhanced bioavailability of silymarin by self-micro emulsifying drug delivery system. 2006;63(3):288-94.

33. Zou DN, Zhang DR, Zhou XH. HPLC determination of entrapment efficiency of Matrine-loaded albumin nanoparticles, Chin. J Pharm Anal. 2008;28(1):93-6.

34. Junghanns JU, Müller RH. Correspondence: Jens-Uwe AH Junghanns. International Journal of Nano medicine. 2008;3(3)295-309.
30. Semalty A, Semalty M, Singh D, Rawat MS, et al. Phospholipids-

35. Microbiological examination - Total colony number SCAN-CM 60:02 SCAN-P 81:02. 2002.

36. Hamouda D, El-Adawi H. Optimization study for the extraction of phenolicsrich silymarin from Silbummarianum. Journal of Medicinal Plants Research. 2013;7(25):1878-85.

37. Sharma K, Ko EY, Assefa AD, Ha S, Nile SH, Lee ET, Park SW. Temperaturedependent studies on the total phenolics, flavonoids, antioxidant activities, and sugar content in six onion varieties. Journal of food and drug analysis. 2015;23(2):243-52.

38. Chen X, Young TJ, Sarkari M, Williams III RO, Johnston KP. Preparation of cyclosporine a nanoparticles by evaporative precipitation into Aqueous solution. International Journal of Pharmaceutics. 2002;242(1-2):3-14.

39. Sarkari M, Brown J, Chen X, Swinnea S, Williams III RO, Johnston KP. Enhanced drug dissolution using evaporative precipitation into aqueous solution. International Journal of Pharmaceutics. 2002;243(1-2):17-31.

40. Corrigan OI, Holohan EM, Sabra K. Amorphous forms of thiazide Diuretics prepared by spray-drying. International Journal of Pharmaceutics. 1984;18(1-2): 195-200.

41. Hancock BC, Parks M. What is the true solubility advantage for amorphous pharmaceuticals? Pharmaceutical Research. 2000;17(4):397-404.

42. Yu L. Amorphous pharmaceutical solids. Preparation, characterization and stabilization. Advanced Drug Delivery Reviews. 2001;48(1):27-42.

43. Hancock BC, Zografi G. Characteristics and significance of the amorphous state in pharmaceutical systems. Journal of Pharmaceutical Sciences. 1997;86(1):1-2.

\section{SUMMARY}

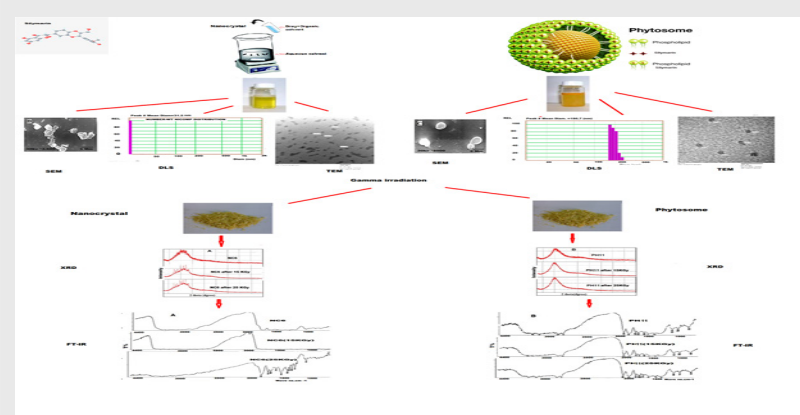

- Preparation of Silymarin as nanoparticle formula.

- Determination of physicochemical characterization of formula.

- Determination of the best soluble and efficient formula.

- Study the effect of gamma radiation on nanoformula.

\section{About Authors}

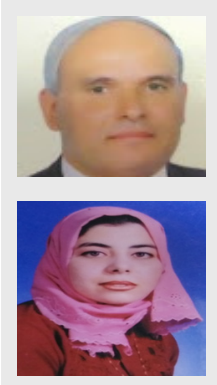

Prof. Dr. Ahmed Ibrahim El-Batal: Professor of Microbial Biotechnology and Nanotechnology at National Center for Radiation Research and Technology, Cairo,Egypt .He is principal investigator of the project ("Nutraceuticals and Functional Foods Production by using Nano/ Biotechnological and Irradiation Processes"and Nanotechnology Research Unit). He graduated from Faculty of Science. Ain Shams University 1979.

Ph.Enas Goodha Eldbaiky: Drug Radiation Research Department, National Center for Radiation Research and Technology (NCRRT), Atomic Energy Authority, Cairo.

Prof. Dr Shahira F. Elmenshawi: Professor Department of Pharmaceutics, Faculty of Pharmacy, Beni-Suef University, Beni-Suef.

Dr. Ahmed M. Abdelhaleem Ali: Department of Pharmaceutics, Faculty of Pharmacy, Taif University, Taif, Saudi Arabia.

Cite this article: El-Batal Al, Elmenshawi SF, Abdelhaleem Ali AM, Eldbaiky EG. Preparation and Characterization of Silymarin Nanocrystals and Phytosomes with Investigation of their Stability using Gamma Irradiation. Indian J of Pharmaceutical Education and Research. 2018;52(4 Suppl 2):s174-s183. 